\title{
АРХЕОЛОГИЯ
}

DOI: https://doi.org/10.15688/jvolsu4.2019.3.1

UDK $902 / 904$

Submitted: 21.02.2018

LBC 63.4(2)

Accepted: 28.06 .2018

\section{THE ENEOLITHIC BURIAL OF MAKSIMOVKA I SOIL BURIAL GROUND FROM THE SAMARA TRANS-VOLGA REGION ${ }^{1}$}

Viktor A. Tsibin

State Budgetary Establishment of Culture "Heritage", Samara, Russian Federation

\section{Anton A. Shalapinin}

Samara State University of Social Sciences and Education, Samara, Russian Federation

\begin{abstract}
Introduction. In the early 1980s the materials of soil burial grounds served as a base for identifying a special Eneolithic period in the history of the Middle and Lower Volga regions. Gathering of source basis on burial Eneolithic complexes is being effected rather slowly. Due to this fact the publication of new information on burial complexes of the Copper Age is quite urgent. This article enters the materials found during the excavations on Maksimovka I soil burial ground situated within the Samara river basin into scientific life. Methods. The collective burial on Maksimovka I burial ground consisted of three or probably four skeletons. They were supine, their legs bent at the knees and their heads oriented towards the North-East. Grave goods included a bone tool, a pressure tool, a sandstone pendant, flint scrapers and a borer, arrowheads with straight or emarginated foundation. Results. While comparing the burial rite with materials of other Eneolithic burial grounds one can see the greatest similarity in the complexes of the Khvalynsk Eneolithic culture (the presence of collective burials, supine position of skeletons with bent legs, orienting the buried people's heads towards the North-East). Leaf-like arrowheads with narrowed bases and a cavity on the foundation were used in a wide range of activities in the Eneolithic period and Early Bronze Age in the Volga-Don interfluve. However they are typical for Caspian and Altatin complexes in the steppe area of the Volga region. Discussion. In accordance with the latest radiocarbon dates concerning the Eneolithic materials of soil burial grounds and settlement monuments one should date the burial on Maksimovka soil burial ground tentatively 5200-4500 BC.

Key words: Eneolithic, steppe Volga region, burial rite, Caspian culture, Khvalynsk culture, Altatine culture.

Citation. Tsibin V.A., Shalapinin A.A. The Eneolithic Burial of Maksimovka I Soil Burial Ground from the Samara Trans-Volga Region. Vestnik Volgogradskogo gosudarstvennogo universiteta. Seriya 4. Istoriya. Regionovedenie. ㄱ. Mezhdunarodnye otnosheniya [Science Journal of Volgograd State University. History. Area Studies. International Relations], 2019, vol. 24, no. 3, pp. 6-16. (in Russian). DOI: https://doi.org/10.15688/jvolsu4.2019.3.1

\section{ПОГРЕБЕНИЕ ЭПОХИ ЭНЕОЛИТА ГРУНТОВОГО МОГИЛЬНИКА МАКСИМОВКА I ИЗ САМАРСКОГО ЗАВОЛЖЬЯ ${ }^{1}$}

\author{
Виктор Александрович Цибин
}

ГБУК «Наследие», г. Самара, Российская Федерация
\end{abstract}




\section{Антон Александрович Шалапинин}

Самарский государственный социально-педагогический университет, г. Самара, Российская Федерация

Аннотация. Материалы грунтовых могильников послужили основой для выделения в начале 80 -х гг. $\mathrm{XX}$ в. особого энеолитического периода в истории Среднего и Нижнего Поволжья. Процесс накопления источниковой базы по погребальным энеолитическим комплексам идет медленными темпами. В связи с этим публикация новых данных о погребальных комплексах медно-каменного века является весьма актуальной. В данной работе вводятся в научный оборот материалы из разведок на грунтовом могильнике Максимовка I, расположенном в бассейне р. Самара. Коллективное погребение на грунтовом могильнике Максимовска I состояло из трех, возможно четырех, костяков. Они лежали на спине с согнутыми в коленях ногами и были ориентированы головой на северо-восток. Погребальный инвентарь состоял из костяного орудия, отжимника, подвески из песчаника, кремневых скребков и проколки, наконечников стрел с прямым или выемчатым насадом. При сравнении погребального обряда с материалами других энеолитических могильников наибольшее сходство наблюдается в комплексах хвалынской энеолитической культуры (наличие коллективных захоронений, положение костяков на спине с завалившимися ногами, ориентировка погребенных головой на северо-восток). Наконечники стрел листовидной формы с зауженным основанием и выемкой на насаде имели широкий диапазон бытования в эпоху энеолита и раннего бронзового века в Волго-Донском междуречье, однако в степной зоне Поволжского региона они характерны для прикаспийских и алтатинских комплексов. На основании имеющихся на данный момент радиоуглеродных дат по энеолитическим материалам грунтовых могильников и поселенческих памятников погребение на грунтовом могильнике Максимовка І в предварительном плане следует датировать 5200-4500 ВС. Вклад авторов. В.А. Цибин - описание погребального комплекса, внесение принципиальных изменений в текст статьи, одобрение окончательной версии; А.А. Шалапинин - интерпретация данных, обзор литературы, написание текста статьи.

Ключевые слова: энеолит, степное Поволжье, погребальный обряд, прикаспийская культура, хвалынская культура, алтатинская культура.

Цитирование. Цибин В. А., Шалапинин А. А. Погребение эпохи энеолита грунтового могильника Максимовка I из Самарского Заволжья // Вестник Волгоградского государственного университета. Серия 4, История. Регионоведение. Международные отношения. - 2019. - Т. 24, № 3. - С. 6-16. - DOI: https://doi.org/ 10.15688/jvolsu4.2019.3.1

Введение. При изучении эпохи энеолита лесостепной и степной зон бассейна р. Волги одно из первостепенных мест занимают материалы погребальных комплексов. Именно результаты раскопок Съезжинского, I и II Хвалынских, Хлопковского и других могильников во многом послужили в начале 80-х гг. $\mathrm{XX}$ в. фундаментом для выделения особого энеолитического периода в истории Среднего и Нижнего Поволжья [8; 17]. В то же время плохая сохранность костных остатков в песчаных и супесчаных почвах и грунтовый характер могильников создают объективные предпосылки для менее динамичного темпа пополнения источниковой базы погребальных комплексов эпохи энеолита по сравнению с памятниками бронзового или раннего железного веков. В связи с этим принципиально важным становится введение в научный оборот новых материалов из разведок и раскопок последних лет. Таковыми являются погребения эпохи энеолита из грунтового могильника Максимовка I. Цель настоящей работы - публи- кация результатов разведок на грунтовом могильнике Максимовка I в 2017 году. В число задач, поставленных авторами входит: описание изученного комплекса, характеристика особенностей погребального обряда и сопутствующего инвентаря и определение его культурно-хронологической атрибуции.

Методы. В связи с тем, что настоящая статья является публикацией результатов разведок, авторы используют традиционные для такого рода работ методы исследования: описательный, типологический, сравнительный.

Грунтовый могильник Максимовка I располагается на северной окраине с. Максимовка в Богатовском районе Самарской области на левом берегу р. Съезжая в 450 м к востоку - северо-востоку от места ее впадения в p. Самара, приток р. Волги (см. рис. 1).

Грунтовый могильник был выявлен в ходе разведочных работ в 2017 г. сотрудниками ГБУК «Наследие». Информация о захоронении поступила от жителя с. Максимовка, который при рытье котлована на приусадебном 


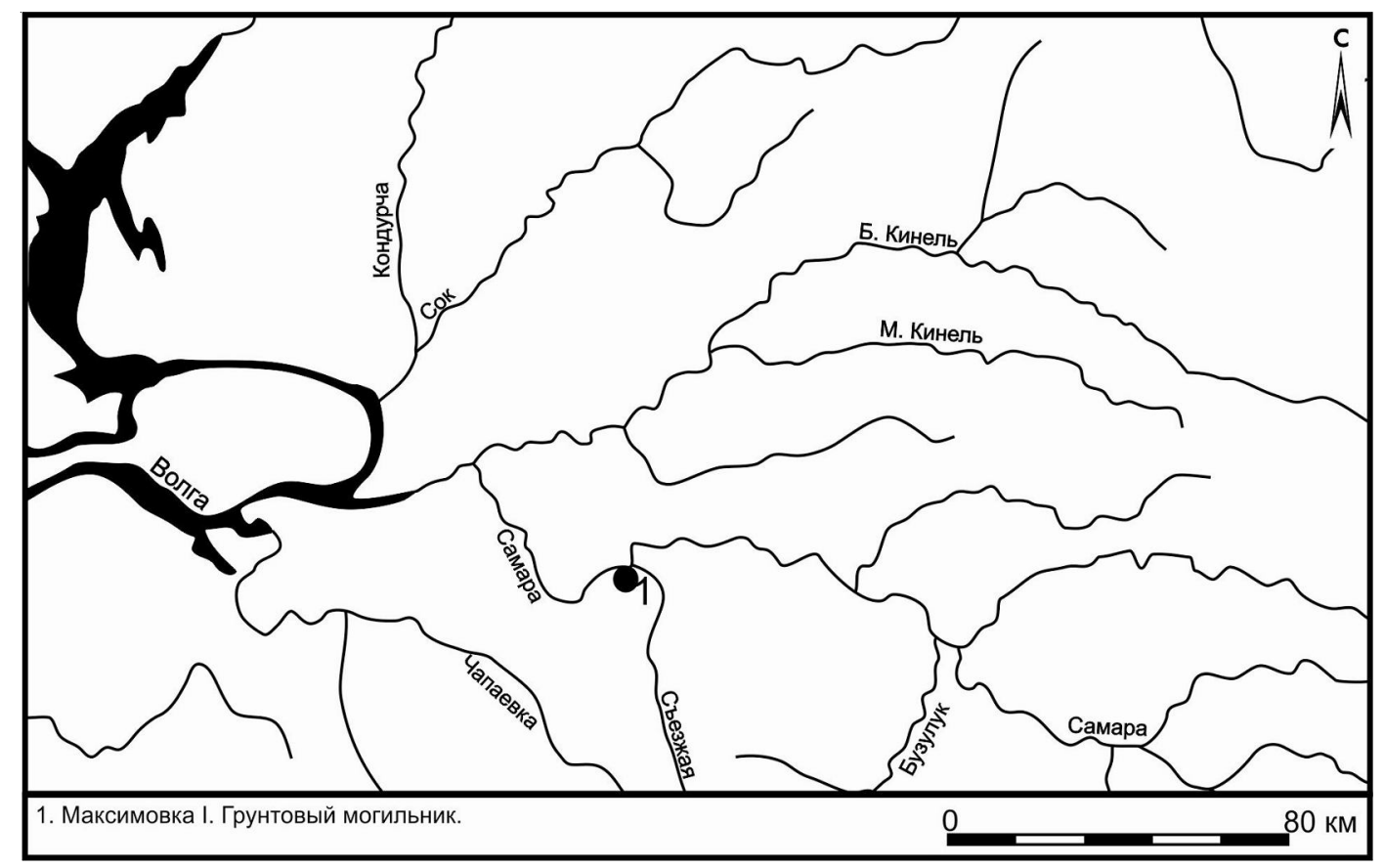

Рис. 1. Местоположение грунтового могильника Максимовка I

Fig. 1. Location of Maksimovka I soil burial ground

участке обнаружил человеческие кости. Авторы настоящей публикации при осмотре котлована собрали подъемный материал, состоящий из четырех наконечников из кварцита и кремня, а также кремневого скребка (см. рис. 3, 1-4). На месте котлована был заложен шурф размерами $4 \times 4$ м, а в связи с расположением части скелета за пределами размеченной площади, в северо-западной части была осуществлена прирезка размерами $0,5 \times 2$ м (см. рис. 2,2$)$.

Стратиграфия рекогносцировочного шурфа следующая (по северной стенке) (см. рис. 2, 1): 1. Дерн мощностью до 6 см. 2. Слой темного гумусированного песка, мощностью от 20 до 36 см. 3. Слой светлого серо-коричневого песка, мощностью от 20 до 45 см. Данный слой расположен под слоем темного гумусированного песка и над материком, а также является заполнением могильной ямы. 4. В восточной части фиксируется переотложенный слой, состоящий из перемешанного темно-коричневого, серого и желтого песка, мощностью до $70 \mathrm{~cm}$. 5. Материк - светло-желтый песок.

В шурфе было обнаружено захоронение, состоящее из трех костяков в непотревоженном состоянии. Кроме того, местным жителем при рытье котлована были изъяты кост- ные остатки еще одного индивида. Центр котлована находился к юго-востоку на расстоянии 20-40 см от изученного захоронения. Не исключено, что изъятые ранее кости и собранный на поверхности инвентарь составляли с указанным погребением один комплекс.

Погребенные располагались в ряд по линии северо-запад - юго-восток (нумерация костяков с востока на запад) (см. рис. 2, 2).

Костяк № 1 находился в юго-восточной части захоронения. Погребенный располагался на спине и был ориентирован верхней частью тулова на северо-восток. Ноги согнуты в коленях и направлены на запад. Фрагменты черепа сильно разрушились и располагались в районе грудной клетки и таза. Кости грудной клетки, рук и таза также сильно фрагментированы. Правая плечевая кость относительно хорошей сохранности ориентирована по линии восток - северо-восток - запад - юго-запад. У левого колена данного костяка был обнаружен кремневый скребок (см. рис. 3, 8). К юговостоку от него южнее бедренной кости располагался каменный отжимник (см. рис. 3, 12), а к югу от таза обнаружено два наконечника (см. рис. $3,5,7)$. К востоку от левой малоберцовой кости костяка фиксировалось аморфное пятно серой супеси размерами $8 \times 12$ см. 

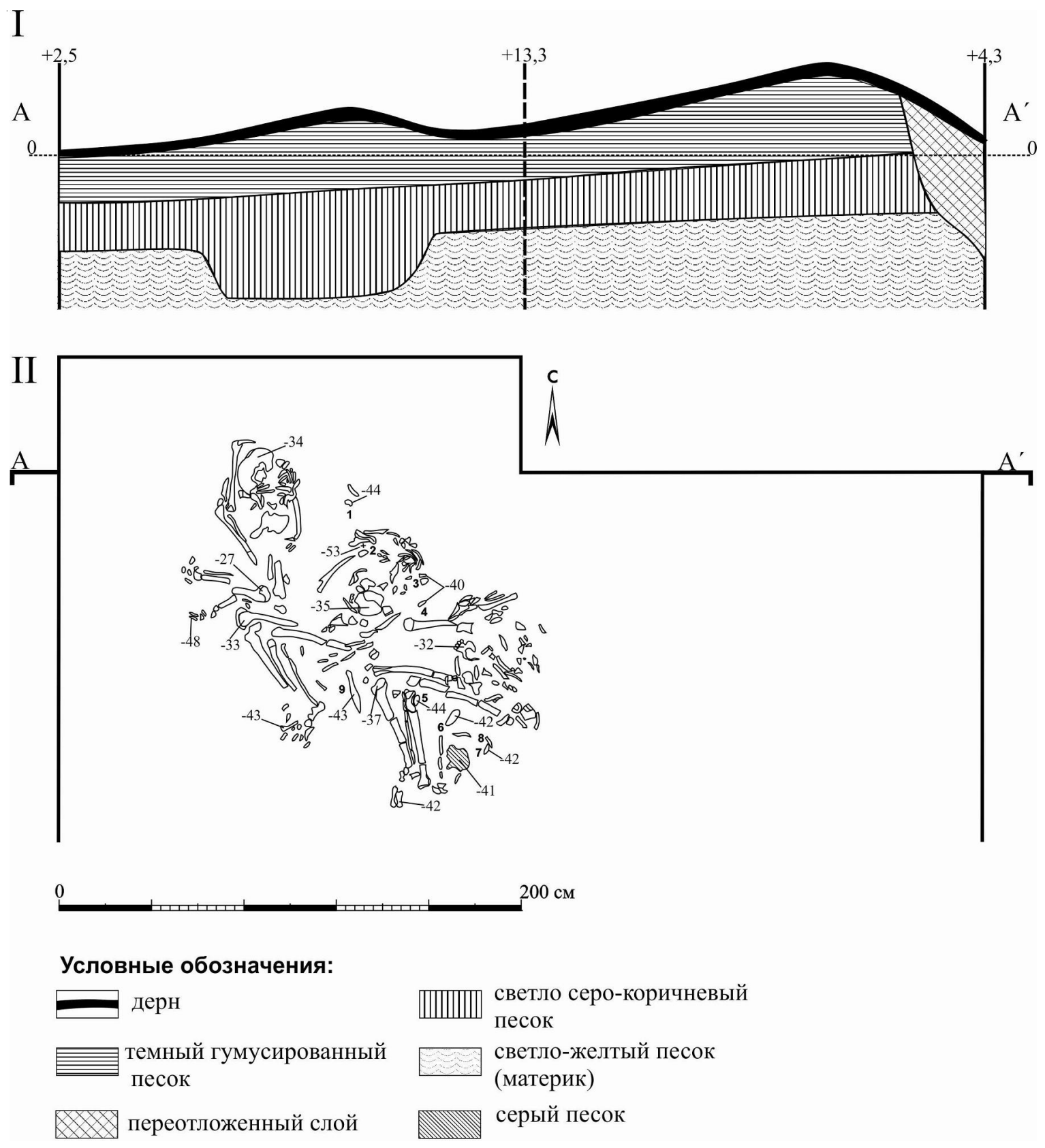

Рис. 2. Северная стенка шурфа (I) и погребение (II)

Fig. 2. The Northern wall of the pit (I) and burial (II)

Костяк № 2 расположен в центре захоронения, ориентирован верхней частью туловища на северо-восток. Скелет находился на спине, кости ног согнуты в коленях и завалились на запад. Череп располагался между костями таза и грудной клеткой. Плечевой отдел сохранился относительно хорошо и находился в анатомическом порядке. От рук сохранились локтевые и лучевые кости, вытянутые вдоль тулова. В костях плечевого отдела располагалась подвеска из песчаника (см. рис. 3, 13). В районе левого плеча находился обломок наконечника (см. рис. 3 , б). К югу обнаружена кремневая проколка (см. рис. 3,11 ). В районе таза и колен располагалось костяное орудие (см. рис. 3,10 ).

Костяк № 3 находился в северо-западной части захоронения. Он ориентирован головой на северо-восток. Погребенный лежал на спине, ноги согнуты в коленях и завалились на восток. Череп располагался в районе грудной клетки и повернут теменем на северо-во- 

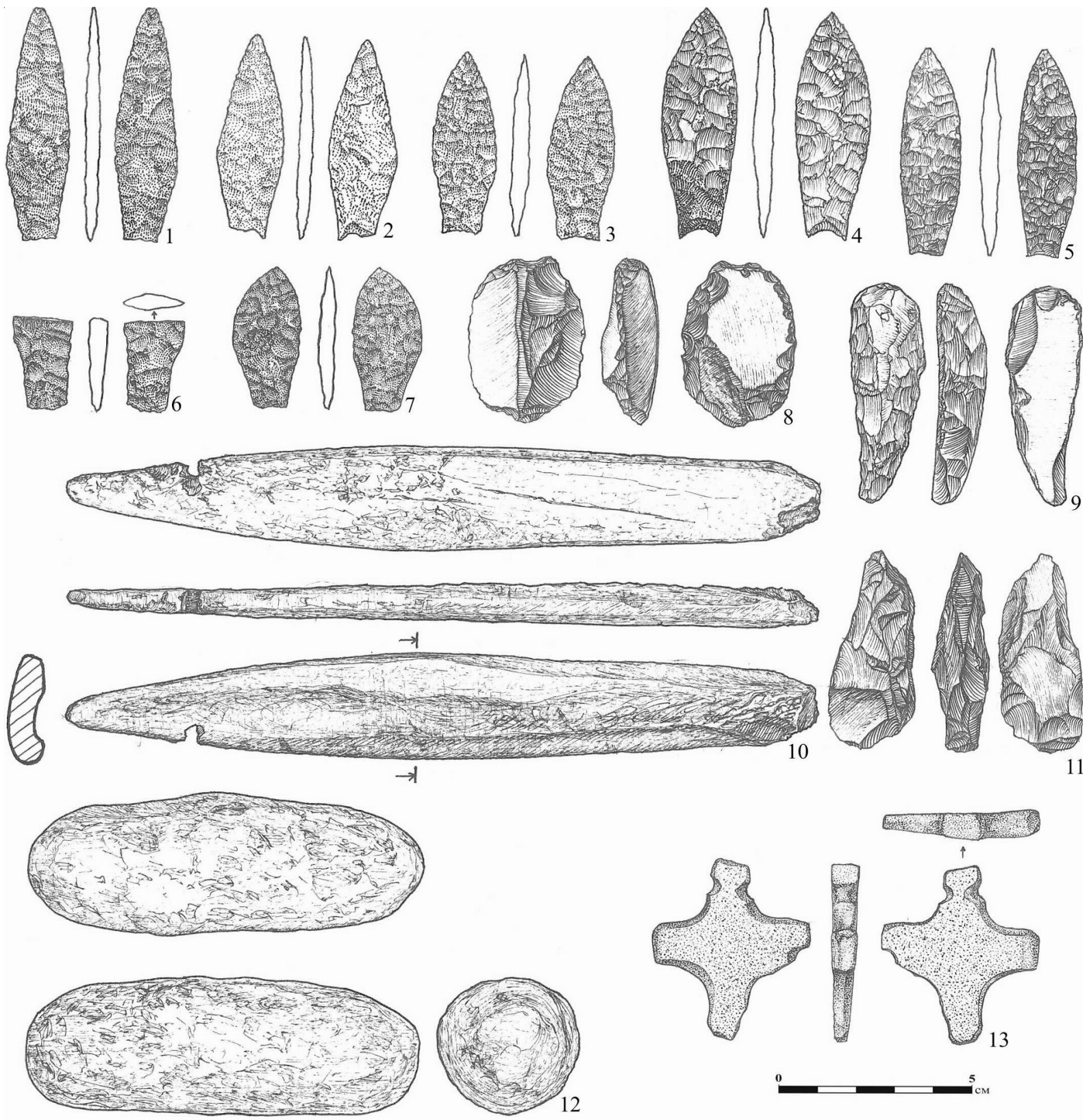

Рис. 3. Инвентарь из погребения

Fig. 3. Grave goods from the burial

сток. Плечевой пояс, грудная клетка и таз в плохой сохранности. Кости рук вытянуты вдоль тулова. Между костяком № 3 и костяком № 2 обнаружен фрагмент неорнаментированной стенки сосуда.

Подъемный материал, относящийся к эпохе энеолита включает четыре наконечника стрел и один скребок.

Первый наконечник изготовлен из кремня серо-коричневого цвета, длинной 6 см, максимальной шириной $2 \mathrm{~cm}$, толщиной $0,3 \mathrm{~cm}$ (см. рис. 3,4$)$. Наконечник имеет листовид- ную форму с зауженным основанием. Основание насада с выемкой.

Второй наконечник выполнен из кварцита желто-коричневого цвета, длиной 6 см, максимальной шириной 1,5 см и толщиной $0,2$ см (см. рис. 3,1$)$. Наконечник имеет листовидную форму с зауженным основанием. Основание насада прямое.

Следующий наконечник также сделан из кварцита желто-коричневого цвета (см. рис. 3,2$)$. Его длина -5 см, максимальная ширина - 1,7 см и толщина 0,2 см. Наконеч- 
ник имеет листовидную форму с зауженным основанием. Основание насада с выемкой, один шип обломан.

Четвертый наконечник изготовлен из кварцита желто-коричневого цвета (см. рис. 3, 3). Его длина $-4,6$ см, максимальная ширина $-1,6 \mathrm{~cm}$, толщина $-0,2$ см. Наконечник имеет листовидную форму с зауженным основанием. Основание насада с выемкой.

Скребок конце-боковой на удлиненном отщепе из кремня темно-серого цвета и белой коркой, длиной 5,5 см, максимальной шириной 1,9 см, толщиной $1 \mathrm{~cm}$. Ретушь рабочего края вертикальная (см. рис. 3, 9).

Инвентарь, обнаруженный в захоронении следующий:

Подвеска (см. рис. 3, 13). Она изготовлена из плитки песчаника коричневого цвета и имеет крестообразную форму. Длина изделия $-4,5$ см, ширина -4 см, толщина $-0,5$ см. Подвеска отшлифована. Грани частично закруглены. Верхний конец имеет выемки для подвешивания. Выемка с нижней стороны зафиксирована у одного из боковых концов. На изделии сохранились небольшие пятна охры.

Костяное орудие (см. рис. 3, 10). Изготовлено из трубчатой кости крупного копытного животного. Длина орудия $-18,5$ см, ширина $-2,5$ см, толщина $-0,9$ см. Изделие имеет подромбическую форму. Один конец приострен, другой обломан. Грани закруглены. В приостренной части изделия имеется выемка шириной 0,4 см и глубиной 0,6 см.

Отжимник (см. рис. 3, 12). Орудие изготовлено из камня зернистой структуры желто-коричневого цвета. Изделие овальное в сечении. Длина орудия -10 см, ширина $-3 \mathrm{~cm}$, толщина $-2,5$ см.

Наконечник стрелы из кремня белого цвета (см. рис. 3, 5). Изделие имеет длину $5,3 \mathrm{~cm}$, максимальную ширину 1,5 см и толщину 0,2 см. Наконечник листовидной формы с зауженным основанием. Основание насада с выемкой.

Наконечник стрелы из кварцита желтокоричневого цвета (см. рис. 3,7 ). Длина изделия - 3,6 см, максимальная ширина $-1,7$ см, толщина - 0,3 см. Наконечник имеет листовидную форму с зауженным основанием. Ocнование насада с выемкой.
Обломок насада наконечника стрелы из кварцита желто-коричневого цвета (см. рис. 3, б). Изделие имеет длину 2,3 см, максимальную ширину 1,5 см и толщину 0,3 см. Насад прямой.

Проколка из кремня темно-серого цвета (см. рис. 3,11 ). Изделие имеет длину 5 см, максимальную ширину 2,1 см и толщину $1,2 \mathrm{~cm}$. Орудие изготовлено на удлиненном отщепе. Острие имеет ретушь со стороны спинки.

Скребок конце-боковой на удлиненном отщепе из кремня темно-серого цвета и белой коркой (см. рис. 3,8 ). Длина орудия 4,2 см, максимальная ширина - 3 см, толщина $-1,2$ см. Ретушь полукрутая.

Сильно фрагментированная неорнаментированная стенка.

Анализ. При установлении культурнохронологической атрибуции захоронения из грунтового могильника Максимовка I определяющую роль играет ориентировка погребенных, положение костяков и специфический набор сопутствующего инвентаря. Наиболее ранними погребениями со схожей ориентировкой и положением костяка в степной зоне Поволжского региона на данный момент являются захоронения на Варфоломеевской стоянке. Особый интерес вызывает коллективное погребение № 4, в котором костяки располагались на спине, один из них имеет слабо согнутые колени и ориентирован головой на северо-восток. Указанное захоронение залегало в верхней части нижнего культурного слоя, содержащего прочерченную и накольчатую неолитическую керамику и перекрыто на данном участке суглинистой прослойкой [31, с. 119]. Со Съезжинским могильником самарской энеолитической культуры сходство наблюдается в северо-восточной ориентировке костяков и в наличии коллективных погребений [6]. С материалами могильника Липовый Овраг параллели прослеживаются не с основной группой энеолитических захоронений, где костяки вытянуты на спине и ориентированы головой на север, а с безинвентарным скорченным погребением № 6, чья культурно-хронологическая атрибуция автором раскопок до конца не была определена [5, с. 12]. Скорченное погребения изучено на могильнике мариупольского времени Екатериновский Мыс [12, с. 12]. Наибольшая близость к мак- 
симовскому захоронению прослеживается в материалах хвалынской культуры. Так, на I Хвалынском могильнике около половины захоронений имеет ориентировку на северо-восток. Умершие в основном располагались на спине с подогнутыми в коленях ногами и вытянутыми вдоль тела руками. Достаточно часты в Хвалынском некрополе коллективные погребения, состоящие из 2-4 костяков [1;26]. На другом могильнике хвалынской культуры Хлопковском северо-восточная ориентировка погребенных преобладает. Здесь костяки также лежат на спине с согнутыми ногами [16, c. 79-89]. Следует указать на энеолитические захоронения с аналогичным погребальным обрядом со стоянки Лебяжинка V (погр. 9, 12), ранее относимые к мариупольскому кругу памятников [7], а в свете последних данных радиоуглеродного анализа, близкие по времени к I и II Хвалынским и Хлопковскому могильникам [29]. Что касается грунтовых погребений лесостепной и степной зон, датируемых поздним энеолитом (Гундоровка, Урочище Красноярка), то для них характерно вытянутое положение костяков на спине. У данных костяков голова ориентирована на восток [4], юго-восток, юг, юг - юго-запад и только в одном случае - на северо-восток [25, с. 293].

Из всех полученных на Максимовке находок для сопоставления с материалами других энеолитических памятников наиболее «перспективным» для определения культурно-хронологической атрибуции являются наконечники стрел с выемкой на насаде. Обломки насадов и целые экземпляры наконечников данного типа в бассейне р. Самары ранее были выявлены на Виловатовской [9, с. 178] и Ивановской $[18$, с. $119 ; 20$, с. 125$]$ стоянках, а также на поселении Найденное Озеро I [3, с. 63]. Указанные памятники содержат разнокультурный энеолитический материал, расположенный на разных хронологических позициях. На энеолитических памятниках Нижнего Поволжья наконечники с выемкой на насаде встречены в комплексах прикаспийской (Передовое, Озинки I, Лебяжий Дол, Орошаемое) и алтатинской (Алтата, Пшеничное) культур [32, c. 156-158, 163, 191, 199]. Подобные наконечники также обнаружены в качестве подъемного материала на Варфоломеевской стоянке $[32$, c. 28$]$ и в энеолитическом слое поселения
Кумыска, содержащем комплексы прикаспийской, хвалынской и среднестоговских культур [32, с. 9-12]. В Северном Прикаспии наконечники с выемкой на насаде известны со сборов с поверхности в окрестностях Нового Караузека [23, с. 120], на памятнике прикаспийской культуры Курпеже-Молла [2, с. 64] и в подкурганном погребении могильника Кривая Лука XV (кург. 3, погр. 1) [30, с. 31]. В Донском регионе они обнаружены на Константиновском поселении [11, с. 112] и в курганном могильнике Каратаево-Сады [14, с. 17]. Таким образом, наконечники стрел с выемкой на насаде имеют достаточно широкий диапазон бытования в Волго-Донском регионе, и датируются эпохой энеолита и раннего бронзового века, однако в степном и лесостепном Поволжье они встречены на памятниках с материалами медно-каменного века. При этом для комплексов хвалынской культуры эти наконечники не характерны [10]. Поскольку наибольшее распространение они получили в энеолите степной зоны Поволжского региона, погребение Максимовского могильника следует связывать происхождением именно с данной территорией.

Для установления хронологической позиции погребения Максимовка I необходимо рассмотреть корпус радиоуглеродных датировок, имеющийся на сегодняшний момент для энеолитических комплексов степного и лесостепного Поволжья. Материалы из энеолитических слоев стоянки Орошаемое имеют следующие даты: 5667士100 BP SPb-1474 (кость

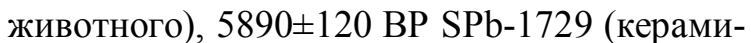
ка), 5806 \pm 26 BP UGAMS-23059 (кость овцы), $5934 \pm 100$ BPSPb-2091 (коллаген) [21, с. 237; 22 , с. 189]. Близко к указанным датировкам определение по С14 по керамике прикаспийского

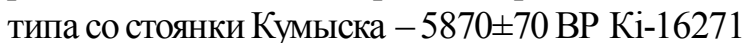
$[24$, c. 55]. Прикаспийская керамика со стоян-

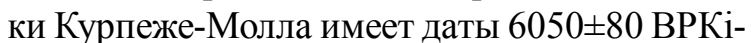
14831 и $6020 \pm 80$ ВРКі-14832 [19, с. 21]. Совпадают с указанными значениями даты по костям человека с I и II Хвалынских и Хлопковского могильников [15, с. $8 ; 27$, с. 123$]$ и по керамике хвалынского типа с поселенческих памятников Поволжского региона [19, с. 23]. Радиоуглеродные даты керамики со стоянки Алтата (5120 70 ВРКі-16493) [24, с. 55] и по-

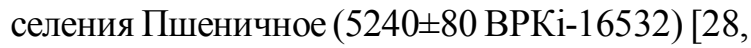


c. 20], вероятно, очерчивают верхнюю границу бытовая в степном Поволжье наконечников с выемчатым основанием. Калиброванные значения указанных датировок укладываются в диапазон 5200-3900 ВС. Учитывая бытование традиции погребения лежать на спине с подогнутыми ногами с ориентировкой головы на северо-восток в степном Поволжье в хроноинтервале $5200-4500$ ВС [13, с. $272-$ 273], захоронение на грунтовом могильнике Максимовка I в предварительном плане следует датировать этим временем.

Выводы. Погребение на грунтовом могильнике Максимовка I состоит из трех, возможно четырех, костяков. Погребенные лежали на спине с согнутыми в коленях ногами с ориентировкой головой на северо-восток. Сопутствующий погребальный инвентарь состоит из костяного орудия, отжимника, подвески из песчаника, кремневых скребков и проколки, наконечников стрел с прямым или выемчатым насадом. Аналогичный погребальный обряд распространен в могильниках хвалынской энеолитической культуры. Наконечники стрел характерны для прикаспийских и алтатинских комплексов степного Поволжья. Погребение на Максимовском грунтовом могильнике предварительно следует датировать 5200-4500 BC.

\section{ПРИМЕЧАНИЕ}

1 Работа выполнена в рамках проекта 33.1907.2017/ПЧ Министерства образования и науки РФ.

The work was supported by project 33.1907.2017/ПЧ of the Ministry of Science and Higher Education of the Russian Federation.

\section{СПИСОК ЛИТЕРАТУРЫ}

1. Агапов, С. А. Хвалынский энеолитический могильник / С. А. Агапов, И. Б. Васильев, В. И. Пестрикова. - Саратов : Изд-во Сарат. ун-та, 1990. - 160 с.

2. Барынкин, П. П. Новые энеолитические памятники Северного Прикаспия / П. П. Барынкин, И. Б. Васильев // Археологические памятники на Европейской территории СССР. - Воронеж : ВГПИ, 1985. - С. 59-75.

3. Барынкин, П. П. Поселение Найденное Озеpo I / П. П. Барынкин, О. В. Кузьмина, А. А. Ластов- ский // Вопросы археологии Поволжья : сб. тр. конф. (г. Самара, 10 авг. - 10 окт. 2017 г.). - Самара : Книжное издательство, 2017. - Вып. 6. -С. 7-108.

4. Богданов, С.В. Энеолитический могильник в урочище Красноярка / С. В. Богданов, А. А. Хохлов // Известия СНЦ РАН. - 2012. - Т. 14, № 3. C. 205-213.

5. Васильев, И. Б. Могильник мариупольского времени в Липовом овраге на севере Саратовской области / И. Б. Васильев // Древности Среднего Поволжья. - Куйбышев : КГУ, 1985. - С. 3-19.

6. Васильев, И. Б. Могильник у с. Съезжее на p. Самаре / И. Б. Васильев, Г. И. Матвеева // Советская археология. - 1979. - № 4. - С. 147-166.

7. Васильев, И. Б. Энеолит / И. Б. Васильев, Н. В. Овчинникова // История Самарского Поволжья с древнейших времен до наших дней. Каменный век. - Самара : СНЦ РАН, 2000. - С. 216-277.

8. Васильев, И. Б. Энеолит Поволжья (степь и лесостепь) / И. Б. Васильев. - Куйбышев : КГПИ, 1981. $-130 \mathrm{c}$.

9. Виловатовская стоянка в лесостепном Заволжье / И. Б. Васильев, А. А. Выборнов, Р. С. Габяшев, Н. Л. Моргунова, Г. Г. Пенин // Энеолит Восточной Европы. - Куйбышев : КГПИ, 1980. C. 151-188.

10. Горащук, И. В. Каменные орудия хвалынской культуры / И. В. Горащук // Хвалынские энеолитические могильники и хвалынская энеолитическая культура. Исследования материалов. - Самара : Поволжье, 2010. - С. 287-356.

11. Кияшко, В. Я. Между камнем и бронзой (Нижнее Подонье в V-III тысячелетиях до н. э.) / В. Я. Кияшко. - Азов : Азовский краеведческий музей, 1994. - 132 с.

12. Королев, А. И. Грунтовый могильник Екатериновский мыс эпохи энеолита в Самарском Поволжье: итоги работ 2013-2016 гг. / А. И. Королев, А. Ф. Кочкина, Д. А. Сташенков // V (XXI) Всероссийский археологический съезд : сб. науч. тр. - Барнаул : Алт. гос. ун-т, 2017. - С. 527-528.

13. Королев, А. И. К вопросу о хронологии и периодизации энеолита степного и лесостепного Поволжья / А. И. Королев, А. А. Шалапинин // Известия СНЦ РАН. - 2014. - Т. 16, № 3. C. 266-275.

14. Курганные погребения раннего бронзового века Нижнего Подонья (свод археологических источников) / сост. А. В. Файферт. - Ростов н/Д, 2014. $-500 \mathrm{c}$.

15. Малов, Н. М. Задоно-Авиловский энеолитический могильник / Н. М. Малов // Археологическое наследие Саратовского края. - Саратов : Научная книга, 2008. - Вып. 8. - С. 3-15.

16. Малов, Н. М. Хлопковский могильник и историография энеолита Нижнего Поволжья / Н. М. Ма- 
лов // Археология Восточно-Европейской степи. Саратов : Научная книга, 2008. - Вып. 6. - С. 32-134.

17. Мерперт, Н. Я. Проблемы энеолита степи и лесостепи Восточной Европы / Н. Я. Мерперт // Энеолит Восточной Европы. - Куйбышев : КГПИ, 1980. - C. 3-26.

18. Моргунова, Н. Л. Ивановская стоянка эпохи неолита - энеолита в Оренбургской области / Н. Л. Моргунова // Энеолит Восточной Европы. Куйбышев : КГПИ, 1980. - С. 104-124.

19. Моргунова, Н. Л. Хронологическое соотношение энеолитических культур Волго-Уральского региона в свете радиоуглеродного датирования / Н. Л. Моргунова, А. А. Выборнов, Н. Н. Ковалюх, В. В. Скрипкин // Российская археология. - 2010. № 4. - С. 18-27.

20. Моргунова, Н. Л. Энеолитические комплексы Ивановской стоянки / Н. Л. Моргунова // Неолит и энеолит Северного Прикаспия. - Куйбышев : КГПИ, 1989.-С. 118-135.

21. Новые данные по неолиту - энеолиту Нижнего Поволжья / А. А. Выборнов, А. И. Юдин, И. Н. Васильева, П. А. Косинцев, М. А. Кулькова, Т. Гослар, Н. С. Дога // Известия СНЦРАН. - 2015. Т. 17, № 3. - С. 235-241.

22. Новые материалы исследований на поселении Орошаемое в Нижнем Поволжье / А. А. Выборнов, А. И. Юдин, И. Н. Васильева, П. А. Косинцев, М. А. Кулькова, Н. С. Дога, А. С. Попов // Известия СНЦ РАН. - 2017. - Т. 19, № 3. - С. 185-190.

23. Новые материалы неолита - бронзы из Северного Прикаспия / П. С. Дубягин, Ф. Д. Чикризов, В. А. Чуринов, И. Б. Васильев, А. А. Выборнов // Волго-Уральская степь и лесостепь в эпоху раннего металла. - Куйбышев : КГПИ, 1982. - С. 95-134.

24. Новые радиоуглеродные даты памятников энеолита, раннего и среднего этапов бронзового века Поволжья и Приуралья / Н. Л. Моргунова, Г. И. Зайцева, Н. Н. Ковалюх, В. В. Скрипкин // Археологические памятники Оренбуржья. - Оренбург : ОГПУ, 2011. - Вып. 9. - С. 53-68.

25. Овчинникова, Н. В. Исследование грунтового могильника у с. Гундоровка в лесостепном Поволжье/ Н. В. Овчинникова, А. А. Хохлов // Тверской археологический сборник. - Тверь : Тверская областная тип., 1998. - Вып. 3. - С. 288-299.

26. Пестрикова, В. И. Хвалынский I энеолитический могильник как исторический источник / В. И. Пестрикова, Д. С. Агапов // Хвалынские энеолитические могильники и хвалынская энеолитическая культура. Исследования материалов. - Самара : Поволжье, 2010. - С. 11-118.

27. Черных, Е. Н. Радиоуглеродная хронология Хвалынских некрополей / Е. Н. Черных, Л. В. Орловская // Хвалынские энеолитические могильники и хвалынская энеолитическая культура. Иссле- дования материалов. - Самара : Поволжье, 2010. С. 121-129.

28. Шалапинин, А. А. Культурно-хронологическое соотношение позднеэнеолитических комплексов Среднего Поволжья : автореф. дис. ... канд. ист. наук / Шалапинин Антон Александрович. Ижевск, 2011. - 25 с.

29. Шишлина, Н. И. Радиоуглеродное датирование образцов из могильника Лебяжинка $\mathrm{V}$ эпохи энеолита: верификация и интерпретация данных / Н. И. Шишлина, М. А. Турецкий, Й. ван дер Плихт // Известия СНЦ PAH.-2017. - T. 19, № 3.-С. 196-202.

30. Шишлина, Н. И. Северо-Западный Прикаспий в эпохубронзы (V-III тысячелетия дон. э.) / Н. И. Шишлина. - М. : Унопринт, 2007. - 400 c.

31. Юдин, А. И. Варфоломеевская стоянка и неолит степного Поволжья / А. И. Юдин. - Саратов : Изд-во Сарат. ун-та, 2004. - 200 с.

32. Юдин, А. И. Поселение Кумыска и энеолит степного Поволжья / А. И. Юдин. - Саратов : Научная книга, 2012. -212 c.

\section{REFERENCES}

1. Agapov S.A., Vasilev I.B., Pestrikova V.I. Khvalynskiy eneoliticheskiy mogilnik [Khvalynsk Eneolithic Burial Ground]. Saratov, Izd-vo Saratovskogo universiteta, 1990. $160 \mathrm{p}$.

2. Barynkin P.P., Vasilev I.B. Novye eneoliticheskie pamyatniki Severnogo Prikaspiya [New Eneolithic Monuments of the North Caspian Region]. Arkheologicheskie pamyatniki na evropeyskoy territorii SSSR [Archaeological Monuments in the European Territory of the USSR]. Voronezh, Izd-vo VGPI, 1985, pp. 59-75.

3. Barynkin P.P., Kuzmina O.V., Lastovskiy A.A. Poselenie Naydennoe Ozero I [Naydennoe Ozero I Settlement]. Voprosy arkheologii Povolzhya [Issues of the Archaeology of the Volga River Region]. Samara, Knizhnoe izdatelstvo, 2017, iss. 6, pp. 7-108.

4. Bogdanov S.V., Khokhlov A.A. Eneoliticheskiy mogilnik v urochishche Krasnoyarka [Aeneolithic Ground Necropolis in Krasnoyarka]. Izvestiya SNTS RAN [Izvestia of Samara Scientific Center of the Russian Academy of Sciences], 2012, vol. 14, no. 3, pp. 205-213.

5. Vasilev I.B. Mogilnik mariupolskogo vremeni v Lipovom ovrage na severe Saratovskoy oblasti [Burial Ground of Mariupol Time in Lipovyy Ravine in the North of Saratov Region]. Drevnosti Srednego Povolzhya [Antiquities of the Middle Volga Region]. Kuybyshev, Izd-vo KGU, 1985, pp. 3-19.

6. Vasilev I.B., Matveeva G.I. Mogilnik u s. Sezzhee na r. Samare [A Burial Ground Near the Village of Sezzhee by the Samara River]. Sovetskaya arkheologiya, 1979, no. 4, pp. 147-166. 
7. Vasilev I.B., Ovchinnikova H.B. Eneolit [The Eneolithic Age]. Istoriya Samarskogo Povolzhya s drevneyshikh vremen do nashikh dney. Kamennyy vek [The History of the Samara Volga Region from Antiquity to Our Days. The Stone Age]. Samara, SNTs RAN, 2000, pp. 216-277.

8. Vasilev I.B. Eneolit Povolzhya [The Eneolithic Age of the Volga Region]. Kuybyshev, Izd-vo KGPI, 1981. $130 \mathrm{p}$.

9. Vasilev I.B., Vybornov A.A., Gabyashev R.S., Morgunova N.L., Penin G.G. Vilovatovskaya stoyanka v lesostepnom Zavolzhe [Vilovotovskaya Site in the Forest-Steppe Trans-Volga Region]. Eneolit Vostochnoy Evropy [Eneolithic Age of East Europe]. Kuybyshev, Izd-vo KGPI, 1980, pp. 151-188.

10. Gorashchuk I.V. Kamennye orudiya khvalynskoy kultury [Stone Tools of the Khvalynsk Culture]. Khvalynskie eneoliticheskie mogilniki $i$ khvalynskaya eneoliticheskaya kultura. Issledovaniya materialov [Khvalynsk Eneolithic Burial Grounds and Khvalynsk Eneolithic Culture. Studies of Materials]. Samara, Povolzhe Publ., 2010, pp. 287-356.

11. Kiyashko, V.Ya. Mezhdu kamnem i bronzoy (Nizhnee Podone v V-III tysyacheletiyakh do n.e.) [Between the Stone and Bronze (Lower Don Region in the $5^{\text {th }}-3^{\text {rd }}$ Thousand BC)]. Azov, Azovskiy kraevedcheskiy muzey, 1994. 132 p.

12. Korolev A.I., Kochkina A.F., Stashenkov D.A. Gruntovyy mogilnik Ekaterinovskiy mys epokhi eneolita v Samarskom Povolzhe: itogi rabot 20132016 gg. [Subsoil Burial Ground Ekaterinovskiy Cape of the Eneolithic Epoch in the Samara Volga Region: Results of the Works of 2013-2016]. V (XXI) Vserossiyskiy arkheologicheskiy sezd: sb. nauch. tr. [5 $5^{\text {th }}\left(21^{\text {st }}\right)$ All-Russian Archaeological Congress. Collected Scientific Papers]. Barnaul, Altayskiy gosudarstvennyy universitet, 2017, pp. 527-528.

13. Korolev A.I., Shalapinin A.A. K voprosu o khronologii i periodizatsii eneolita stepnogo i lesostepnogo Povolzhya [On the Chronology and Periodization of the Eneolithic of the Steppe and ForestSteppe Volga Region]. Izvestiya SNTS RAN [Izvestia of Samara Scientific Center of the Russian Academy of Sciences], 2014, vol. 16, no. 3, pp. 266-275.

14. Fayfert A.V. Kurgannye pogrebeniya rannego bronzovogo veka Nizhnego Podonya (svod arkheologicheskikh istochnikov) [Kurgan Burials of the Early Bronze Age of the Lower Don (Code of Archaeological Sources)]. Rostov-on-Don, 2014. 500 p.

15. Malov N.M. Zadono-Avilovskiy eneoliticheskiy mogilnik [Zadono-Avilovsky Eneolithic Burial Ground]. Arkheologicheskoe Nasledie Saratovskogo Kraya [Archaeological Heritage of the Saratov Region]. Saratov, Nauchnaya kniga Publ., 2008, vol. 8, pp. 3-15.
16. Malov N.M. Khlopkovskiy mogilnik i istoriografiya eneolita Nizhnego Povolzhya [Khlopkovskiy Burial Ground and the Historiography of the Eneolithic of the Lower Volga Region]. Arkheologiya Vostochno-Evropeyskoy stepi [Archaeology of the Eastern European Steppe]. Saratov, Nauchnaya kniga Publ., 2008, vol. 6, pp. 32-134.

17. Merpert N.Ya. Problemy eneolita stepi i lesostepi Vostochnoy Evropy [Problems of the Eneolithic Steppe and Forest-Steppe of Eastern Europe]. Eneolit Vostochnoy Evropy [The Eneolithic of Eastern Europe]. Kuybyshev, Izd-vo KGPI, 1980, pp. 3-26.

18. Morgunova N.L. Ivanovskaya stoyanka epokhi neolita-eneolita v Orenburgskoy oblasti [Ivanovskaya Site of the Neolithic-Eneolithic Epoch in Orenburg Region]. Eneolit Vostochnoy Evropy [The Eneolithic of Eastern Europe]. Kuybyshev, Izd-vo KGPI, 1980, pp. 104-124.

19. Morgunova N.L., Vybornov A.A., Kovalyukh N.N., Skripkin V.V. Khronologicheskoe sootnoshenie eneoliticheskikh kultur Volgo-Uralskogo regiona $\mathrm{V}$ svete radiouglerodnogo datirovaniya [Chronological Correlation of the Eneolithic Cultures in the Volga-Urals Region in the Light of Radiocarbon Dating]. Rossiyskaya arkheologiya, 2010, no. 4, pp. 18-27.

20. Morgunova N.L. Eneoliticheskie kompleksy Ivanovskoy stoyanki [Eneolithic Complexes of Ivanovskaya Site]. Neolit i eneolit Severnogo Prikaspiya [Neolithic and Eneolithic of the Northern Caspian]. Kuybyshev, Izd-vo KGPI, 1989, pp. 118-135.

21. Vybornov A.A., Yudin A.I., Vasileva I.N., Kosintsev P.A., Kulkova M.A., Goslar T., Doga N.S. Novye dannye po neolitu-eneolitu Nizhnego Povolzhya [New Data on the Neolithic-Eneolithic of the Lower Volga Region]. Izvestiya SNTs RAN [Izvestia of Samara Scientific Center of the Russian Academy of Sciences], 2015, vol. 17, no. 3, pp. 235-241.

22. Vybornov A.A., Yudin A.I., Vasileva I.N., Kosintsev P.A., Kulkova M.A., Doga N.S., Popov A.S. Novye materialy issledovaniy na poselenii Oroshaemoe v Nizhnem Povolzhe [New Research Materials in Oroshaemoe Settlement in the Lower Volga Region]. Izvestiya SNTS RAN [Izvestia of Samara Scientific Center of the Russian Academy of Sciences], 2017, vol. 19, no. 3, pp. 185-190.

23. Dubyagin P.S., Chikrizov F.D., Churinov V.A., Vasilev I.B., Vybornov A.A. Novye materialy neolita bronzy iz Severnogo Prikaspiya [New Materials of the Neolithic-Bronze from the Northern Caspian]. VolgoUralskaya step i lesostep $v$ ehpokhu rannego metalla [The Volga-Ural Steppe and Forest-Steppe in the Era of Early Metal]. Kuybyshev, Izd-vo KGPI, 1982,pp. 95-134.

24. Morgunova N.L., Zaytseva G.I., Kovalyukh N.N., Skripkin V.V. Novye radiouglerodnye daty pamyatnikov 
eneolita, rannego i srednego etapov bronzovogo veka Povolzhya i Priuralya [New Radiocarbon Dates of the Eneolithic, Early and Middle Bronze Age Monuments of the Volga and Ural Regions]. Arkheologicheskie pamyatniki Orenburzhya [Archaeological Monuments of Orenburg Region]. Orenburg, Izd-vo OGPU, 2011, iss. 9, pp. 53-68.

25. Ovchinnikova N.V., Khokhlov A.A. Issledovanie gruntovogo mogilnika u s. Gundorovka v lesostepnom Povolzhe [Study of a Soil Burial Ground in the Village of. Gundorovka in the ForestSteppe Volga Region]. Tverskoy arkheologicheskiy sbornik [Tver Archaeological Collection]. Tver, Tverskaya oblastnaya tipografiya, 1998, iss. 3. pp. 288-299.

26. Pestrikova V.I., Agapov D.S. Khvalynskiy I eneoliticheskiy mogilnik kak istoricheskiy istochnik [Khvalynsky I Eneolithic Burial Ground as a Historical Source]. Khvalynskie eneoliticheskie mogilniki $i$ khvalynskaya eneoliticheskaya kultura. Issledovaniya materialov [Khvalynsk Eneolithic Burial Grounds and Khvalynsk Eneolithic Culture. Studies of Materials]. Samara, Povolzhe Publ., 2010, pp. 11-118.

27. Chernykh E.N., Orlovskaya L.V. Radiouglerodnaya khronologiya Khvalynskikh nekropoley [Radiocarbon Chronology of Khvalynsk Necropoleis]. Khvalynskie eneoliticheskie mogilniki $i \quad k h v a l y n s k a y a$ eneoliticheskaya kultura. Issledovaniya materialov [Khvalynsk Eneolithic Burial
Grounds and Khvalynsk Eneolithic Culture. Studies of Materials]. Samara, Povolzhe Publ., 2010, pp. 121-129.

28. Shalapinin A.A. Kulturno-khronologicheskoe sootnoshenie pozdneeneoliticheskikh kompleksov Srednego Povolzhya: avtoref. dis. ... kand. ist. nauk [The Cultural-Chronological Relationship of the LateEneolithic Complexes of the Middle Volga Region. Cand. hist. sci. abs. diss.]. Izhevsk, 2011. 25 p.

29. Shishlina N.I., Turetskiy M.A., Plikht J. van der. Radiouglerodnoe datirovanie obraztsov iz mogilnika Lebyazhinka $V$ epokhi eneolita: verifikatsiya $\mathrm{i}$ interpretatsiya dannykh [Ams-Radiocarbon Dating of Samples from the Middle Volga Eneolithic Burial Ground Lebyazhinka V: Data Verification and Interpretation.]. Izvestiya SNTS RAN [Izvestia of Samara Scientific Center of the Russian Academy of Sciences], 2017, vol. 19, no. 3, pp. 196-202.

30. Shishlina N.I. Severo-Zapadnyy Prikaspiy v epokhu bronzy (V-III tysyacheletiya do n.e.) [NorthWestern Caspian Region in the Bronze Age $\left(5^{\text {th }}-3^{\text {rd }}\right.$ Millennium BC)]. Moscow, Unoprint Publ., 2007. 400 p.

31. Yudin A.I. Varfolomeevskaya stoyanka $i$ neolit stepnogo Povolzhya [Varfolomeevskaya Site and the Neolithic Steppe Volga]. Saratov, Izd-vo Saratovskogo universiteta, 2004. 200 p.

32. Yudin A.I. Poselenie Kumyska i eneolit stepnogo Povolzhya [Kumyska Settlement and the Eneolithic of the Steppe Volga Region]. Saratov, Nauchnaya kniga Publ., 2012.212 p.

\section{Information about the Authors}

Victor A. Tsibin, Director, State Budgetary Establishment of Culture "Heritage", Bratyev Korostelevykh St., 112, 443041 Samara, Russian Federation, tsibinva@mail.ru, https://orcid.org/0000-0001-9601-4228

Anton A. Shalapinin, Candidate of Sciences (History), Researcher, Research Department, Samara State University of Social Sciences and Education, M. Gorkogo St., 65/67, 443099 Samara, Russian Federation, anton-shalapinin@ro.ru, https://orcid.org/0000-0001-9434-7811

\section{Информация об авторах}

Виктор Александрович Цибин, директор ГБУК «Наследие», ул. Братьев Коростелевых, 112, 443041 г. Самара, Российская Федерация, tsibinva@mail.ru, https://orcid.org/0000-0001-9601-4228

Антон Александрович Шалапинин, кандидат исторических наук, научный сотрудник научно-исследовательской части, Самарский государственный социально-педагогический университет, ул. М. Горького, 65/67, 443099 г. Самара, Российская Федерация, anton-shalapinin@ro.ru, https://orcid.org/0000-0001-9434-7811 